\title{
Prevention of hospital-acquired and central line- associated bloodstream infections in the intensive care unit through chlorhexidine gluconate washcloth bathing: a systematic review and meta-analysis
}

EP Afonso ${ }^{1 *}, \mathrm{~K} \mathrm{Blot}^{2}, \mathrm{~S} \mathrm{Blot}{ }^{3,4}$

From ESICM LIVES 2015

Berlin, Germany. 3-7 October 2015

\section{Background}

Bloodstream Infection and Central Line-Associated Bloodstream Infection (BSI/CLABSI) in Intensive Care Units (ICUs) are associated with clinical and economic burden. Chlorhexidine gluconate body washing with washcloths (CHG-WC) has been described as potentially effective towards reducing the spread of infection. Current systematized evidence has not fully ascertained the impact of CHG-WC in bacteremia within the ICU. We have systematically assessed the evidence on the effectiveness of CHG-WC in reducing total HABSI/ CLABSI in the ICU.

\section{Objectives}

To systematically review the effect of CHG-WC on total HABSI/CLABSI risk in the ICU.

\section{Methods}

Medline, EMBASE, Cochrane library (CENTRAL) and Web of science databases were searched using variations of key terms Chlorhexidine washcloths, ICU, BSI and CLABSI. Eligible trials implemented CHG-WC in ICUs using a randomized crossover study design and reported total HABSI and CLABSI rates per patient days. Methodological quality of studies was assessed using Cochrane Risk of Bias assessment tool. Random effects meta-analysis calculated odds ratios (OR) and 95\% confidence intervals

${ }^{1}$ Cambridge University Hospitals - Rosie Hospital, Neonatal Intensive Care Unit, Cambridge, United Kingdom

Full list of author information is available at the end of the article
(CI) for total HABSI and CLABSI rates between control (regular washcloth bathing) and treatment groups (CHGWC). Results of 4 eligible studies were included in the final analysis.

\section{Results}

All 4 eligible studies were large randomized control trials encompassing 706 events in 22850 patients from 15 adult and 10 paediatric ICUs. Three studies describe a reduction in total HABSI/CLABSI on patients who received CHG-WC bathing. In one study this reduction is not significant.

\section{Conclusions}

Current data suggests that the use of CHG-WC may be associated with an overall risk reduction of total HABSI and CLABSI, in adult/paediatric ICUs. However, conflicting data remains from the most recent randomized controlled trial, and even though this can be related to discrepancies in study design and outcome reporting, more trials are needed in order to ascertain the usefulness of CHG-WC bathing in the ICU.

\section{Authors' details}

${ }^{1}$ Cambridge University Hospitals - Rosie Hospital, Neonatal Intensive Care Unit, Cambridge, United Kingdom. ${ }^{2}$ Ghent University, Faculty of Medicine and Health Sciences, Ghent, Belgium. ${ }^{3}$ Ghent University, Dept. of Internal Medicine, Faculty of Medicine and Health Science, Ghent, Belgium, Belgium. ${ }^{4}$ The University of Queensland, Burns Trauma and Critical Care Research Centre, Brisbane, Australia. 


\begin{tabular}{|c|c|c|c|c|c|c|c|c|}
\hline \multirow{2}{*}{ Study or Subgroup } & \multicolumn{2}{|c|}{ Treatment } & \multicolumn{2}{|c|}{ Control } & Weight & $\begin{array}{l}\text { Odds Ratio } \\
\text { IV, Random, } 95 \% \mathrm{CI}\end{array}$ & \multicolumn{2}{|c|}{$\begin{array}{c}\text { Odds Ratio } \\
\text { IV, Random, } 95 \% \mathrm{CI}\end{array}$} \\
\hline & 14 & 2210 & 27 & 2119 & $8.6 \%$ & $0.49[0.26,0.94]$ & & \\
\hline Climo 2013 & 140 & 24931 & 208 & 25000 & $36.1 \%$ & $0.67[0.54,0.83]$ & $\rightarrow$ & \\
\hline Milstone 2013 & 66 & 15057 & 107 & 16024 & $25.6 \%$ & $0.65[0.48,0.89]$ & & \\
\hline Noto 2015 & 100 & 19202 & 117 & 20721 & $29.7 \%$ & $0.92[0.71,1.20]$ & & \\
\hline Total $(95 \% \mathrm{Cl})$ & & 61400 & & 63864 & $100.0 \%$ & $0.71[0.58,0.88]$ & & \\
\hline Total events & 320 & & 459 & & & & & \\
\hline $\begin{array}{l}\text { Heterogeneity: } \mathrm{Tau}^{2} \\
\text { Test for overall effect }\end{array}$ & $\begin{array}{l}0.02 ; \mathrm{Chi} \\
\mathrm{z}=3.20\end{array}$ & $\begin{array}{l}i^{2}=5.3 \\
(P=0 .\end{array}$ & $\begin{array}{l}2, \mathrm{df}=3 \\
001)\end{array}$ & $(P=0.1$ & $15) ; 1^{2}=$ & & $\begin{array}{l}0.10 .20 .5 \\
\text { avours } \mathrm{CHC} \text { bathing }\end{array}$ & $1 \frac{2}{2}$ \\
\hline
\end{tabular}

Figure 1 Overall impact of CHG-WC in HABS/CLABSI.

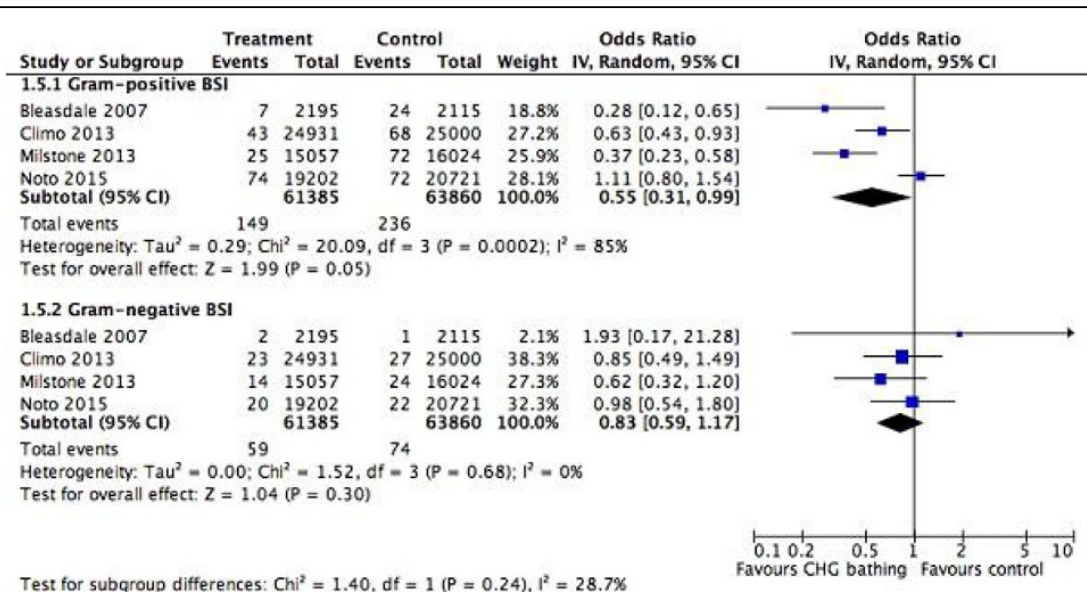

Figure 2 Subgroup analysis.

Published: 1 October 2015

\section{References}

1. Climo MW, Yokoe DS, Warren DK, Perl TM, Bolon M, Herwaldt LA, et al: Effect of daily Chlorhexidine bathing on hospital-acquired infection. $N$ Engl J Med 2013, 368(6):533-542.

2. Bleasdale SC, Trick WE, Gonzalez IM, Lyles RD, Hayden MK, Weinstein RA: Effectiveness of chlorhexidine bathing to reduce catheter-associated bloodstream infections in medical intensive care unit patients. Arch Intern Med 2007, 167(19):2073-2079.

3. Milstone AM, Elward A, Song X, Zerr DM, Orscheln R, Speck K, et al: Daily Chlorhexidine bathing to reduce bacteraemia in critically ill children: a multicentre, cluster-randomised, crossover trial. Lancet 2013, 381(9872):1099-1106.

4. Noto MJ, Domenico HJ, Byrne DW, Talbot T, Rice TW, Bernard GR, et al: Chlorhexidine Bathing and Health Care-Associated Infections: A Randomized Clinical Trial. JAMA 2015, 313(4):369-378,

doi:10.1186/2197-425X-3-S1-A446

Cite this article as: Afonso et al.: Prevention of hospital-acquired and central line-associated bloodstream infections in the intensive care unit through chlorhexidine gluconate washcloth bathing: a systematic review and meta-analysis. Intensive Care Medicine Experimental 2015 3(Suppl 1):A446.

\section{Submit your manuscript to a SpringerOpen ${ }^{\circ}$ journal and benefit from:}

- Convenient online submission

- Rigorous peer review

- Immediate publication on acceptance

- Open access: articles freely available online

- High visibility within the field

- Retaining the copyright to your article

Submit your next manuscript at $>$ springeropen.com 